\title{
Project Effective and Alternative Secondary Education Modules: A Way Future Forward to Contextualized Teaching and Learning of Social Studies
}

\author{
Gary P. Abelarde ${ }^{1} \&$ Ruth A. Ortega-Dela Cruz ${ }^{2}$ \\ ${ }^{1}$ Department of Education, Division of Cabuyao, Pulo Elementary School, City of Cabuyao, Laguna, \\ Philippines 4025 \\ ${ }_{2}^{2}$ Institute for Governance and Rural Development, College of Public Affairs and Development, University \\ of the Philippines Los Baños, Domingo M. Lantican Ave. College, Laguna, Philippines 4031 \\ Correspondence: Ruth A. Ortega-Dela Cruz, University of the Philippines Los Baños, Laguna, Philippines \\ 4031. \\ Email: raortegadelacruz@up.edu.ph
}

Doi: $10.23918 /$ ijsses.v8i2p149

\begin{abstract}
The study used qualitative research design to examine the Project Effective and Alternative Secondary Education (EASE) modules vis-a-vis the K-12 curriculum in teaching Social Studies 6. Content analysis sheets were used to analyse the learning outcomes, teaching-learning activities and assessment tasks utilized in the K-12 curriculum and the Project EASE modules. Moreover, a semi-structured questionnaire was used to determine the challenges of the teachers in teaching Social Studies 6 . Based on the findings of the study, the K-12 curriculum in Social Studies 6 and the Project EASE modules share similarities and differences. The teachers said that they find it challenging to use the Project EASE modules because of its inadequate number, inappropriateness of learning tasks to the context, errors in the content, and poor academic performance of the pupils. Hence, there is a need to revise the Project EASE modules. The revision includes a review of the contents, alignment of the learning outcomes, and providing appropriate assessment tasks relevant to the level of the maturity and intelligence of the Grade 6 pupils. Once these issues are addressed, the Project EASE modules will become a useful tool towards contextualized teaching and learning of Social Studies 6.
\end{abstract}

Keywords: Contextualized, K-12 Curriculum, Teaching and Learning, Social Studies

\section{Introduction}

The quest for effective instructional materials has been happening since time immemorial and still being carried out due to the constant changes in the educational system of the country. Educators spend a lot of time, effort, and money to comply with the standards of teaching and to deliver instruction to the learners in the best way possible. One challenging job for the teachers is to provide the best instructional materials to their pupils who have not mastered the competencies. However, instructional materials for intervention programs in most cases are only limited or completely lacking which leads to insufficient performance on the part of the teachers according to National Teachers Institute (2004 in Atienza, et.al, 2016). With this,

Received: May 11. 2021

Accepted: June 22, 2021

Abelarde, G. P., \& Ortega-Dela Cruz, R.A.O. (2021). Project Effective and Alternative Secondary Education Modules: A Way Future Forward to Contextualized Teaching and Learning of Social Studies. International Journal of Social Sciences \& Educational Studies, 8(2), 149-164. 
the teachers are resorting from utilizing the best alternative instructional materials for the class. These materials may or may not be aligned to the newly implemented curriculum in Grade 6.

School Year 2017-2018 has been a tough school year for Grade 6 teachers in the Philippines because it is the first year of implementing the K-12 Program in Grade 6. Armed only by the lessons learned in a weeklong K-12 seminar and a piece of curriculum guide downloaded from the Learning Resources Management and Development System (LRMDS) Web Site, the said teachers went through a lot of preparations just to make sure that the competencies needed to be taught each day are well delivered to the pupils. No teaching guides, manuals, and learning materials were distributed making it an extra challenge for them. Without the necessary resources, teaching-learning processes were not maximized resulting to failure in achieving the objectives for each day. These failures to reach the mastery level require intervention activities which is another problem for the teachers because of no necessary materials available. With this, the Schools District Supervisor assigned to Social Studies suggested the utilization of Project Effective and Affordable Secondary Education modules or the Project EASE modules for instructional and intervention activities.

The Project EASE was a joint undertaking of the BSE (Bureau of Secondary Education), DECS (Department of Education, Culture and Sports), and SEAMEO INNOTECH (Southeast Asian Ministers for Educational Innovation and Technology) with the objectives of designing and developing an alternative learning for the learners in the secondary level who have difficulty of coming to school because of socioeconomic, geographical and physical circumstances (UNESCO and the Asia/Pacific Cultural Centre for UNESCO, 2000). It means that instead of coming to school regularly, the Project EASE will offer a distance learning system for these students. Moreover, it was also undertaken to provide an avenue for the advanced students who find the conventional learning system too slow or boring and would like to study based on their own paces. This system of distance learning utilizes the use of interactive modules which are based on the current curriculum of DECS in secondary.

EASE is semi-contractual meaning the learner and the teacher will have an agreement that while the former is on school leave, the learner should study and pass the modules before continuing the normal classes in the school (Bureau of Secondary Education, 2008). EASE is also distance learning therefore the learner assumes the responsibility to study on his own set of modules that corresponds to the lessons the regular class shall take. EASE is modularized learning hence it uses a set of user friendly, self-learning modules, so arranged from the simple to the complex that makes it easy for any kind of learner, fast, average, or slow, to locate his learning entry point. Moreover, EASE is learner-directed and teacher-facilitated. This is why the teacher monitors the learner's progress and sees to it that scheduled meetings are conducted, monitoring feedback is utilized, and quality standards are being observed. Lastly, EASE supplements but does replace the regular learning system.

The study explores the relevance of the Project EASE modules to the current K-12 curriculum in Social Studies 6 . These modules have been used in the secondary level as materials in teaching the concepts of Social Studies. However, due to the implementation of the K-12 Program, the competencies in each grade level were adjusted and changed. Some competencies taught in Social Studies 6 were found in the previously utilized Philippine Secondary Learning Competencies (PSLC) for first year high school while others came from the Philippine Elementary Learning Competencies (PELC) for Grades 4-6. With these 
changes, instructional materials used in the secondary level were suggested by the Department of Education to be used in Grade 6 due to the lack of learning and teaching resources.

It has been reported by the Learning Resources Management and Development Section of the Department of Education that the Project EASE modules were effective as instructional materials in the secondary level due to the availability of the said materials. Now that they are being utilized in the elementary level especially Social Studies 6, several questions arose and needed immediate answer.

This study sought answers to the following research questions:

1. Are the Project EASE modules parallel with the K-12 curriculum in Social Studies 6 in terms of teaching-learning activities, assessment tasks and learning outcomes?

2. What are the challenges faced by the teachers in Social Studies 6 using the Project EASE modules?

3. How can the Project EASE modules be contextualized?

The study aimed to examine the Project EASE modules in teaching Social Studies 6. Specifically, it: (i) described K-12 curriculum and the Project EASE modules in terms of teaching-learning activities, assessment tasks, and learning outcomes; (ii) determined the challenges faced by the teachers in teaching Social Studies 6 using the Project EASE modules; and (iii) compared K-12 curriculum and the Project EASE modules in terms of teaching-learning activities, assessment tasks, and learning outcomes.

\section{Materials and Methods}

\subsection{Research Design}

The study employed qualitative research design to gather relevant data. Semi-structured interviews were used to gather focused, qualitative textual data. This method offers a balance between the flexibility of an open-ended interview and the focus of a structured ethnographic survey.

\subsection{Instrumentation}

Content analysis sheets were used to describe and analyse the learning outcomes, teaching-learning activities and assessment tasks utilized in the K-12 curriculum and the Project EASE modules. Moreover, a semi-structured questionnaire was used to determine the challenges of the teachers in teaching Social Studies 6

\subsection{Participant of the Study}

To achieve the purpose of the study, purposive sampling was utilized. The participants were four teachers who had been teaching Social Studies 6. They were chosen because they had the first-hand experiences that provided the needed data for the study.

\subsection{Data Analysis}

First, the K-12 curriculum in Social Studies 6 was examined using the content analysis sheet for curriculum. Then, the Project EASE modules were also subjected to content analysis. Content analysis is a research tool used to determine the presence of certain words, themes, or concepts within some given 
qualitative data (i.e. text). Using content analysis, researchers can quantify and analyse the presence, meanings and relationships of such certain words, themes, or concepts (Columbia University, n.d.). The researcher compared the curriculum and the module. Teachers in Social Studies 6 were subjected to semistructured interview for the researcher to gather data about the challenges these teachers faced in teaching the abovementioned subject.

\section{Results and Discussions}

\subsection{The K-12 curriculum in Social Studies}

\subsubsection{Teaching-Learning Activities}

Just like the curricula of other learning areas under the K-12 Program of the Department of Education, the curriculum in Social Studies was based on the goal of Education for All 2015 and the K-12 Philippine Basic Education Curriculum Framework. Its goal according to the K-12 curriculum Guide (CG) is to produce a functionally literate and developed Filipino who embodies the 21 st century skills like critical thinking, rationality, accountability, productivity, love of nature, nationalism and humanitarianism with national and global perspective taking into consideration the historical and social issues. Constructivism, collaborative learning, contextual and experiential learning, and the utilization of thematic-chronological methodology, conceptual, critical, integrative, interdisciplinary, and multidisciplinary approaches were the strategies used in the curriculum as stipulated in the CG.

As mentioned above, Social Studies 6 curriculum is anchored to the theory of constructivism because it gives importance to learner as the agent who plays pivotal role in the learning process, rather than trying to get the power from the teacher. According to constructivism, learning is the result of individual mental construction, whereby the learner learns by matching 'new' against 'given' information and establishing meaningful connection, rather than by internalizing mere given information to regurgitate later (Jalilzadeh et al, 2011). This is also the reason why the curriculum of Social Studies is spiral. In constructivist thinking, learning is inescapably affected by the context and the beliefs and attitudes of the learners.

The curriculum also encourages collaborative learning, which is one of the main features of K-12 curriculum. Here, learners are taught that success is found not only in the outcome, but in the process. The learning objectives are proofs that Social Studies 6 curriculum features collaborative learning. Contextual and experiential learning are another outstanding characteristic of this curriculum. Content standards offer contextual learning while performance standards offer experiential learning.

\subsubsection{Assessment Tasks}

Although there are no specified assessment tasks in this curriculum, by looking at the learning competencies where these assessment tasks should be based on, it suggests a wide array of assessment tasks to utilize that may be in group or individual and in any form like the traditional paper-pencil assessment as in the case of multiple choice and identification, or in the form of authentic assessment like journals, portfolios, or performance assessments. Traditional assessment refers to the conventional methods of testing which usually produces written document, such as quizzes or exams (Quansah, 2018). Standardized test like achievement tests are also examples of traditional assessment. These comprise tests 
given to students by teachers to measure how much the pupils have learned. The most widely used traditional assessment tools include multiple-choice tests, true/false tests, short answers, and essays.

According to the American Psychological Association \& National Council on Measurement in Education (1999 in Quansah, 2018), authentic or performance assessments are product and behaviour-based measurements based on settings designed to emulate real-life contexts or conditions in which specific knowledge or skills are applied. Performance assessment is seen as having better possibilities to measure complex skills and communication, which are considered important competencies and disciplinary knowledge needed today.

\subsubsection{Learning Outcomes}

The curriculum is divided into four quarters, each part consists of the contents, content standards, performance standards, learning competencies, code, and suggested learning materials. The contents pertain to the topics that are discussed in each grading period. These contents are based on the themes formed by the National Council for Social Studies. In first quarter, topics like geographical location and territory of the Philippines, liberalism, Propaganda Movement, the Katipunan Society, the FilipinoSpanish and Filipino-American Revolution are discussed. Second quarter discusses the American occupation of the Philippines, the Commonwealth, and the Japanese occupation of the Philippines. The Third Philippine Republic is discussed in the third quarter while martial law, EDSA Revolution and the contemporary problems and challenges of the Philippines are discussed in the fourth quarter.

Content standard pertains to what pupils are expected to know, do, and understand. It answers the question "what should the pupils know and be able to do?" Each quarter has one content standard.

Performance standard is about what pupils should create, add value to and transfer. It answers the question "how well must students do their work?" Each content standard is paired with one performance standard. It means that there is also one performance standard per quarter.

Learning competencies are specific statements of knowledge, process/skills, and attitude that students are expected to demonstrate to attain the content standard. These are the objectives to be mastered by the learners each day. Although there is only one specific objective each lesson, the teachers are encouraged to add another two objectives based on the objective given or based on the content. The first quarter has eleven learning competencies, the second has nine, the third has seven and the fourth has eight. These learning competencies are based on the contents, content standards and performance standards in each quarter.

\subsection{The Project EASE Modules}

\subsubsection{Teaching-Learning Activities}

The Project Effective and Alternative Secondary Education (EASE) modules have an interactive approach. The tone is conversational and there are activities in each part where the answer key is located at the back part of the module to enable the learners correct their own work. This is because the Project EASE modules are designed as an alternative learning system for secondary school students who cannot report to their 
classes regularly, for justifiable reasons: part-time job, illness in the family, seasonal work, distance from school, calamitous events, peace and order problem, absence of regular public transportation, and the like. The first page of the module contains the name of the module, the grade level, the topic and the name and $\log$ o of Bureau of Secondary Education which is under the Department of Education.

The next part gives the overview of the lesson which includes the review, the presentation of the lessons, objectives, and pre-test. Each module contains more than two lessons based on the major topic indicated on the first page. Moreover, one module may contain more than one objective depending upon the number of the lessons and the coverage of the topic. The pre-test assesses the learner's knowledge of the topic which is in the form of identification, matching type, and multiple-choice items. The number of items depends on the number of lessons and the coverage of the topic.

The next part introduces the first lesson to be discussed and the specific objectives for that lesson. Then, there comes the first exercise called Pag-isipan Mo (Think About It). It is some sort of a motivation in the form of mental activity like puzzles, jumbled letters, picture analyses and the like. Then, the module discusses about the topic in a conversational way. In this part, facts and concepts are presented to the learners. After the discussion, the learner is required to do the second activity. Activities here may include picture or situational analysis, or the learner may answer questions based on the lessons learned earlier.

The next part is the generalization. Concepts are highlighted here and presented in a bullet form. Then, there is the application. The module may require the learner to draw a map, make a table, answer a specific question, discuss a concept, enumerate some facts, complete sentences, and other related form of assessment.

After the application, the module will present again another topic and will follow the flow of events above. When all the lessons are discussed, the latter part of the module is the evaluation which contains the concepts learned from all the lessons. It might be in the form of multiple choice, identification, or matching type of test which has 20 items. The module then congratulates the learner for finishing this specific topic.

The researcher noticed that The Project EASE modules are constructively aligned. Constructive alignment happens when the learning activities that were asked students to engage in help them to develop the knowledge, skills and understandings intended for the unit and measured by the assessment (Biggs, 2014). If assessment drives students' learning, then students are most likely to achieve the intended outcomes if the assessment is aligned with the intentions.

\subsubsection{Assessment Tasks}

The modules utilize traditional type of assessment tasks. This includes the multiple choices and identification which usually open each lesson as a pre-test. The application and evaluation parts which usually in the form of multiple choices, matching type, essay, and true/false items.

Traditional assessments are indirect and inauthentic (Bailey, 1998 in Quansah, 2018). Traditional assessment is mostly one-shot, speed-based, and norm-referenced. That is, they measure what learners can do at a particular time. However, test scores do not show the progress the learner is making. Consequently, they cannot tell what difficulties the students had during the test. 


\subsubsection{Learning Outcomes}

The learning outcomes in the Project EASE are clearly stated at the beginning of the modules. The title gives the learners the content which usually covers a specific period in the Philippine history. For example, EDSA Revolution is discussed in one module while other modules may discuss the Third Republic, Filipino-Spanish War, the Fall of Bataan, and others. The specific objectives for a lesson were also written before the discussion part. All objectives are smart, measurable, attainable, result-oriented and time bound.

\subsection{Comparison of the Project EASE modules and K-12 curriculum in Social Studies}

\subsubsection{On Teaching-Learning Activities}

Although the K-12 curriculum has no specified teaching-learning activities because it is just an outline of the contents, content standards, performance standards and learning competencies. It clearly stated that these indicators are based on the theory of constructivism whereby the learner learns by matching 'new' against 'given' information and establishing meaningful connection, rather than by internalizing mere given information to regurgitate later (Jalilzadeh et al, 2011).

$\mathrm{K}-12$ curriculum is a spiral one. Meaning, there is an iterative revisiting of topics, subjects, or themes throughout the course (Harden, 2009). These topics, subjects and themes get more difficult as the learner gets promoted to higher grade levels. Moreover, new learning is related to the previous learning. With this, the researcher can say that the learner constructs new learning by making a connection from the previous learning to the present set of facts and concepts. This is a clear sign of the influence of constructivism.

Constructivism is also evident in the Project EASE modules. The activities are crafted to connect prior from present concepts. The review provides the learners with the necessary facts and concepts they learned in the past that will be of use for new learning in a specific module. Aside from the review, the activities will also make them view of the past as the doors to learn new things in the present. Taking for example the Activity 1 in Module 12 with the direction: Study the picture. What does it say about the start of the American occupation of the Philippines? How do you feel about it? This activity will make them think of their prior learning about colonialism in the Philippines which they have learned in previous grade levels especially in Grade 5.

As mentioned earlier, K-12 curriculum is designed for contextual and experiential learning. This was reiterated during the Regional Mass Training of the Education Program Supervisor in Social Studies and gave instructional freedom to the teachers to make changes to the suggested teaching guides and manuals to tailor fit for their specific group of learners. This makes the K-12 curriculum relevant today since Filipino learners are living in different places with different contexts. For example, a pupil in a rural area has very different experiences, environment and social context from a pupil who lives in the city. This means that they should have subjected to different instructional method to learn the same content, content standards, performance standards and learning competencies.

Contextualization makes the curriculum flexible. For example, the learning competency: Relate the problems, issues and challenges of the Third Republic that can impede the development of the country to present can trigger a very different experiential learning from the learners who leaves in different 
communities. The teacher, to make the instruction contextualized, should include in the discussions the challenges faced by the community where the learners live during the Third Republic and the present time. A farm community has different set of challenges from a fishing village. The same is true with the urban community.

In contrast, the Project EASE modules are not contextualized in a certain community where the learners live. This is because these modules are designed to be used anywhere in the Philippines rather than in a specific community. Learning will become more meaningful if these modules will relate the concept with the learners' current setting. Upon reading all the modules, the researcher found out that many of the activities are not contextualized. For example, Module 12 which discusses about the national heroes who fought against the Americans would become more relevant if it included the local heroes in the community or town where the learners are living.

Another thing is the level of difficulty of the activities in the modules. Since these modules are specially designed to supply instruction for the secondary level, the activities are also crafted to the level of maturity these high school learners have. Taking for example the Activity 1 in Module 6 with the direction: Based on what you have learned when you were first year high school in Philippines History, describe in a short essay what Magellan did upon his arrival in the Philippines. With this direction, the learners will be confused and will not understand the activity leading to failure to master the concept.

It is also mentioned earlier that K-12 curriculum was designed to allow collaborative learning where two or more learners learn or attempt to learn together (Dillenbourg, 1999). This method allows learning to become more meaningful because as two or more learners share ideas and solve problems while enriching their social skills. For example, the learning competency: value the roles of every citizen in promoting the development of the country in a creative way can be best learned through collaborative effort. With their group mates, they will brainstorm about the different roles of the citizens in keeping the development of the country and execute the output in a creative way like roleplaying, musical or round table discussion.

On the other hand, the Project EASE modules do not allow collaboration since these were originally designed for individual instruction. All activities included in these modules are to be accomplished by only one learner at a time with no way for them to collaborate. With this, there is no chance to develop the social skills of the learners while learning together or solving the problems together.

\subsubsection{On Assessment Tasks}

There has been no mention of the types of assessment tasks in the K-12 curriculum but content standards, performance standards and learning competencies demand the teachers of the combination of traditional paper-pencil and authentic assessment tasks. Taking for example the learning competency: able to write short essay about the policies and contributions of a certain president to the development of society and the country. It really requires the learners to write a short paragraph. On the other hand, the competency: value the contribution of the distinct Filipinos who fought for freedom may be assessed through roleplaying or a short skit. In this way, the learners are enabled to demonstrate their competency in a more authentic setting or in a more contextualized way. 
The Project EASE modules, on the other hand, employ purely traditional assessment tasks. Items like multiple choices, identification, completing the table and enumeration are some of the most common types of assessment that can be found in the modules. One factor is that many of the authentic assessment tasks require collaborative learning like the role playing, debate, round table discussions, and others. With no room for collaborative learning, the Project EASE modules chose to use traditional assessment tasks.

Another thing the researcher think why there is lack of authentic assessment in the Project EASE modules is because these modules are designed for the learners to easily assess their own learning. Therefore, at the latter part of every module are the specific answers for the activities. Using authentic assessment may require every module to have rubrics or specific criteria which may become subjective if the learners check their own works. To avoid subjectivity and to get more accurate result, they opted to utilize the traditional assessment tasks.

\subsubsection{On Learning Outcomes}

K-12 curriculum clearly stated the learning outcomes needed to be mastered by the learners since it is basically a list of the contents, content standards, performance standards and learning competencies. Although the teachers are given the instructional freedom to alter the suggested teaching guides, manuals and learner materials, the learning outcomes should never sacrifice rather should be benefited from the said alteration or change. This freedom given by the Department of Education is for the learners to grab their maximum opportunity to learn or master the competencies no matter what their current settings are.

In addition, since the abovementioned curriculum does not indicate whether the specific learning outcome for the day is cognitive, affective, or psychomotor, the education program supervisor in social studies demanded the social studies teachers to identify it and make two more learning outcomes based on the specific for the day. For example, the learning competency: value the contribution of the distinct Filipinos who fought for freedom falls under the affective domain. Hence, the teacher should be able to create two more competencies from this one like: analyse the contribution of the distinct Filipinos who fought for freedom (cognitive) and create a poster about the contribution of the distinct Filipinos who fought for freedom (psychomotor).

Just like the K-12 curriculum, the Project EASE modules have specific learning outcomes stated at the beginning of every lesson. These learning outcomes are in the form of cognitive, affective, and psychomotor domains, too. Though, the modules do not consider creating learning outcomes with complete domains per topic.

Another salient point to consider regarding the learning outcomes with respect to the learning competencies between the K-12 curriculum and the Project EASE modules is that many of the learning outcomes are not parallel. Their contents are the same but the expected learning competencies/learning outcomes are very different. For example: the content is about the commonwealth government, the learning outcomes in the K-12 related to this content are to: analyse the contribution of the commonwealth government; discuss the programs of the government during the conquest to the Philippines and explain how the government solved the social and economic issues during the commonwealth. However, in the Project EASE modules, the learning outcomes are to: determine the processes undertaken to adopt the 
Philippine Constitution 1985; describe the framework and features of the commonwealth Government; give the important undertakings in the achievement of the desire for independence.

If the learning outcomes are not parallel, the assessment tasks are also not parallel leading to irrelevance of the Project EASE modules to the curriculum in Social Studies 6. But some of the learning outcomes found in the modules, though slightly different, can be validated as parallel to the curriculum. For example, the learning competencies from the curriculum: analyse the important events in the fight of the Filipinos during the Filipino-American War / determine the events leading to the Filipino-American War can be matched to analyse the origin of Filipino-American War, which is found in Module 12.

\subsection{Challenges Faced by the Teachers in Teaching Social Studies 6 Using the Project EASE Modules}

\subsubsection{Inadequate Number of Modules}

One hundred percent of the participants said that due to the lack of the quantity of the Project EASE modules, teaching Social Studies 6 became difficult. These Project EASE modules, suggested instructional materials by the Department of Education, are available only online and can be downloaded at the website of Learning Resources Management System (LRMDS) of the DepEd. Due to the lack of resources (bond papers for printing and reproduction), the teachers downloaded and printed just several copies of them which are not enough to a group of more than 45 learners.

Teacher A underscored this problem when he said:

"I really wanted to print enough copies of the modules for my classes but because each module consists of 40-70 pages, I can't. The school does not provide us with enough bond paper for these specific modules. I personally bought the paper that I used to print my daily lesson plans and other reports. I can't add more; I have a family to provide for their needs."

Teacher B sought the support of the school for additional copies of these modules when she said:

"Last June 2018, I approached our school property custodian to ask for a couple of reams of bond paper for the reproduction of these modules. He said that the available paper at the stock room is for the printing of reports only. This made me sad because I was trying to provide our learners with enough materials. You see, until now, DepEd does not supply us with instructional materials."

The root cause of this problem is the exclusion of the reproduction of these learning materials to the Maintenance and Other Operating Expenses (MOOE) Allocations of the school. MOOE is the monthly budget for each school in the Philippines to fund its expenses. The exclusion happens when the school head prioritizes other items to be purchased by the school. In school year 2018-2019, the principal's priorities are the procurement of smart televisions per classroom, additional printers in each grade levels, attendance to seminars and trainings of the teachers, participation of the pupils to local and national academic and nonacademic contests, keeping the school safe and secure, and purchase of cleaning materials. 
This issue should be addressed immediately since the learners will be directly affected by it. Although the priorities are for the betterment of school and instruction, the very reason of the existence of the educational institution was put aside. Why not treat first the immediate illness then go beyond it afterwards. With this, the school is moving away from learner-centeredness and preferred to excel outside school without making sure that the learners left have enough needs to learn new concepts and ideas.

Inappropriateness of Learning Tasks to the Context

Two out of four participants agreed that they find it hard to utilize the learning tasks in the Project EASE modules. This is because these modules are designed to fit for the needs and maturity of the high school learners, many of the activities are inappropriate for the Grade 6 pupils.

Teacher B confirmed that she sometimes changes the learning tasks especially if she is in the lower sections because she feels that pupils will not finish answering the activities. She said:

"Even I can't answer some of the activities in the modules. So, what I did was I changed these difficult activities to easier ones especially when I teach the lower section. How can they answer higher order thinking skills when the simple recall or understanding of the previous topics are very hard for them?"

Teacher D, however, took it to other aspect of the context by stating that the pupils do not enjoy learning because there is an absence of localization among the modules. This makes other learners difficult to relate learning within themselves. She said:

"When I was observed by our district supervisor, he was looking for the contextualization in my lesson. I told him that this lesson was lifted from the Project EASE modules. He asked me why I did not include the experiences of the community to the Japanese during their occupation in the Philippines. Well, I just answered him that I would do it next time. Poor EASE Modules, no localization."

The root cause of this problem is the absence of contextualization in Project EASE module wherein the main reason is that these modules are not made for Grade 6 pupils rather, it was designed for the high school students.

Section 5 of Republic Act 10533 otherwise known as the Enhanced Basic Education Act of 2013 stated:

- The curriculum shall be culture-sensitive;

- The curriculum shall be contextualized and global;

- The curriculum shall be flexible enough to enable and allow schools to localize, indigenize and enhance the same based on their respective educational and social contexts.

Since the K-12 curriculum is already contextualized and flexible enough, instructional materials should meet the demands of the curriculum. This is why contextualization is a very important aspect of today's instruction and the higher DepEd officials are seeking the employment of contextualization in the daily lessons. 
This is now the job of subject teachers - to contextualize their instruction and instructional materials. Contextualization comes in two levels: localization and indigenization. Localization is the freedom of schools or local education authorities to adapt the curriculum to local conditions (Taylor, 2004). Localize by using the materials found in the locality like for example, instead of using the seeds in the activity, use the seashells found at the seashore. Another example is the use of local information like songs, stories, and people. DepEd Order No. 32, series of 2015 defines localization as the process of relating learning content specified in the curriculum to local information and materials in the learners' community. Indigenization as stipulated in DepEd Order No. 32; series of 2015 is:

"The process of enhancing curriculum competencies, education resources, and teachinglearning processes in relation to the bio-geographical, historical, and socio-cultural context of the learners' community. Indigenization may also involve the enhancement of the curriculum framework, curriculum design, and learning standards of subject areas, guided by the standards and principles adhered to by the national curriculum."

This is the highest degree of contextualization. It involves the enhancement of themes included in the curriculum to fit for the learners of a certain community especially the indigenous groups in the Philippines. The community practices and culture are discussed first before the discussion of the learning competencies in the curriculum. For example, before discussing the Greek constellations, community's own calendar of star patterns and its background are discussed first.

\subsubsection{Errors in the Content}

One hundred percent of the participants found out that the Project EASE modules contain errors especially in the accuracy of historical events and dates. This is one major offense since the subject Social Studies is very specific when it comes to the correct historical events. This is affirmed by Teacher $\mathrm{C}$ with her statement:

"I was discussing about the Philippine Revolution when one of my pupils exclaimed, "Ma'am, I think you are telling the wrong date of the Cry of Balintawak. My teacher in Grade 5 told me a different date." I looked for that specific topic in the books and found out that the Project EASE Module provided me with incorrect data. I felt ashamed because I was teaching them with wrong information. What I did afterwards was I always check the information with other books."

This is seconded by Teacher A when he said:

"While I was preparing for my presentation, I was confused about the data I read in the module. I checked if my background information about the topic is wrong. I found that some data about the presidents in the Third Republic written in the Project EASE modules are wrong. I reported it to the subject coordinator to validate my claim."

Although the SEAMEO-INNOTECH and Bureau of Secondary Education claimed that the making of these modules are carefully done, the researcher believes that it lacks proper review from the people who have the capability to validate the data and concepts found in the modules resulting to some errors. 
Teachers A, B, C and D agreed that the errors are just minimal and can be corrected by them. This is a must, even if the error is only one, it is necessary to correct it so that the learners will not be able to learn the wrong data or concept and might be carried to the next level.

Poor Academic Performance of the Learners

One hundred percent of the participants agreed that it is a challenge for them to teach a group of leaners with poor academic performance in social studies. They shared that many learning competencies intended to be learned in the lower grade level are not mastered by the pupils. Since the curriculum has spiral progression, it is indeed difficult for them to master the current competencies because they still struggle to learn the previous ones. With this, the gap develops, and it becomes wider as the competencies become more complex and more difficult. Teacher A admitted that it is difficult to bridge the gaps caused by the inability of the learners to master the competencies. He stated:

"When I opened my lesson and asked them about the two principles of acquiring nationality which are the jus sanguinis and jus soli, they were all staring at me as if that was the first time, they heard those terms which should not be because nationality is one of the contents of Social Studies 4. I received no answer. I was disappointed.

Another, when our topic was about secularization of the Filipino friars during the Spanish Era, I asked them as a review of what is a fraile (Spanish friar). This is their topic in Grade 5 and this is a simple recall of a very common word in social studies. I got nothing. I almost cried because I have to introduce them again to the basic concepts and continue my lesson afterwards. The result - we took the topic in three days!"

These sad teaching experiences from Teacher A were confirmed by Teacher D when she narrated her disappointing experiences in teaching social studies that revealed how low the academic performance of the learners in social studies:

"Aside from the fact that they hardly participate in discussions, the results of the assessment and evaluation are unsatisfactory. At times, the learners who have not mastered the competencies were subjected to intervention programs. The same sets of learners tend to not master the competencies. I have also four learners who struggle to read even in Tagalog/Filipino. These pupils, I think should not be promoted to Grade 6 unless their performance becomes better. Well, this is the product of mass promotion which was earlier implemented by the Department of Education."

While instruction is the answer to poor academic performance of the pupils, their past learning experiences play a bigger role to maximize their learning today. This is the reason why $\mathrm{K}-12$ curriculum is designed in spiral progression and the teachers encouraged to employ the theory of constructivism in their instruction.

Although poor academic performance is caused by any or a combination of motivational orientation, selfesteem/self-efficacy, emotional problems, study habits, family background, teacher consultation and poor interpersonal relationship according to Sokan (2003 in Asikhia, 2010), this should have been addressed 
earlier to avoid the worsening effects of it. Teacher B said that because of the inability of the learners to master the competencies in the lower grade levels, the teachers teach again the prerequisite topics. This distracts the budget of work in Grade 6 which adds additional sessions for each competency thereby sacrificing the other competencies.

\section{Conclusions}

The study presents a comprehensive examination of the Project EASE modules in teaching Social Studies 6 by describing and comparing K-12 curriculum and the Project EASE modules in terms of teachinglearning activities, assessment tasks, learning outcomes; and determining the challenges faced by the teachers in teaching Social Studies 6 using the modules. It has been found out that the K-12 curriculum and the Project EASE modules share similarities in terms of: (i) teaching-learning activities, as both utilize constructivism to provide meaningful learning experiences and employ contextualization; (ii) assessment tasks, as both use traditional form of assessment; and (iii) learning outcomes, as both are specific, measurable, attainable, result-oriented, and time-bound.

However, a lot of differences between the K-12 curriculum and the Project EASE modules were identified such as:

1. Teaching-learning activities, as the modules are generally contextualized in the Philippine setting while the curriculum is contextualized in a certain community where the specific learners live. Another thing is the level of difficulty whereas some activities in the modules are too difficult for an average grade 6 pupil.

2. Assessment tasks, as the modules use traditional type of assessment only while the curriculum encourages the use of both traditional and authentic types of assessments.

3. Learning outcomes of the modules and curriculum are not parallel. Many competencies found in the modules do not answer any of the competencies stated in the curriculum.

Teachers teaching Social Studies 6 with the use of The Project EASE modules faced a lot of challenges. These challenges are:

1. Inadequate number of modules. This is due to the exclusion of the reproduction of these learning materials to the Maintenance and Other Operating Expenses (MOOE) allocations of the school.

2. Inappropriateness of learning tasks to the context. Teachers said that some of the learning tasks are not appropriate to the level of intelligence and maturity of the Grade 6 pupils. This is because these modules are tailor-fitted for the high school students.

3. Errors in the content. Many facts are inconsistent due to the lack of the person in authority to review the modules.

4. Poor academic performance of the learners. This is caused by the inability of the learners to master the learning competencies in the previous grade levels.

With these findings, the study concluded that the Project EASE modules are not appropriate for teaching Social Studies 6 because there are a lot of mismatches between the K-12 curriculum and these modules in terms of teaching-learning activities, assessment tasks and learning outcomes. This study presented the actual situation of the teachers in a public elementary school, in a developing country where they faced 
several challenges in teaching Social Studies 6 using the suggested resources by the Department of Education - the Project EASE modules. Since there are still no available teaching and learning materials and guides, teachers may revise these modules based on the following proposed revisions:

First, the learning outcomes of the Project EASE modules and K-12 curriculum must match. The curriculum must be the one to dictate the learning outcomes because it is the standard that must be followed. Since there is no problem about the contents of the modules in terms of its alignment to the curriculum, the learning competencies will be the focus of the revision.

Second, the teaching-learning activities should also undergo revisions. Here, the teachers should include localization and indigenization as levels of contextualization. Local information like poems, stories, experiences of the people in the community and others should be included in the activities. This is important especially if the topic is about the experiences of people during the Spanish, American and Japanese occupation in that specific area. Martial law is also a very good topic to include localization. Further, many activities in the modules are too difficult for the Grade 6 learners and may take them long time to answer. The teachers may also consider changing these activities to meet the level of the learners they are intended to use. Since this revision will make these modules specially designed for Grade 6 learners, might as well make them collaborative and allow peer learning for a more meaningful learning experience. Collaborative and experiential learning are two of the major features of the K-12 Program of the Department of Education.

Third, to allow for constructive alignment, the teachers should also include in their revision the assessment tasks. Since the Project EASE modules only utilize traditional type of assessment, make the other items authentic. Teachers may request their pupils of the portfolios to monitor their own progress and may include assessment tasks which involve performances and real-life scenarios. This will also pave the way for collaborative and experiential learning.

Fourth, to solve the problem about the minimal quantity of the modules, the teachers may write a letter requesting the members of the school planning committee to include the budget for reproduction in the next list of items to be purchased by the Maintenance and Other Operating Expenses allocations of the school. They may ask the help of the administrative aides for the operation of the photocopy machine in the office to minimize the expenses.

Fifth, regarding poor academic performance of the learners in social studies which is a perennial problem of the school for many years, the teachers maybe needing the help of the school governing council to raise their concern. Indeed, intervention programs per grade level for these learners with poor academic performance should be strictly implemented. As of now, the school is very lax in implementing intervention programs.

To be able to fit for the needs of the Grade 6 pupils, the identified issues must be addressed first. Once these issues are addressed, the Project EASE modules will become a useful tool to the maximization of teaching and learning in Social Studies 6 especially today that there are still no available teaching guides, teaching manuals, learners' materials, and other instructional materials supposedly provided by the Department of Education. There is no better way to contextualize the Project EASE modules than revise 
some of its parts which hinder its compatibility with the Grade 6 learners. It is not an easy job, but it will be a fruitful one and will be a great help towards contextualized teaching and learning of social studies.

\section{References}

Asikhia, O. A. (2010). Students and teachers' perception of the causes of poor academic performance in Ogun State secondary schools [Nigeria]: Implications for counseling for national development. European Journal of Social Sciences, 13(2), 229-242.

Atienza, M. R., Buenaventura, J. S., Faner, D. F., Garcia, G. R., \& Roxas, M. C. (2016). Instructional materials being used by private and public preschool teachers in selected elementary schools in Lipa City. Retrieved 11 May 2019 from https://www.slideshare.net/JemiahBuenaventura/instructional-materials-being-used-bypreschool-teachers-in-selected-schools-in-lipa-city

Biggs, J. (2014). Constructive alignment in university teaching: HERDSA Review of Higher Education, $1,5-22$.

Bureau of Secondary Education. (2008). EASE Handbook. Retrieved 10 February 2019 from https://www.slideshare.net/larryeusebio/ease-handbook

Columbia University. (n.d.). Content Analysis. Retrieved 17 May 2019 from https://www.mailman.columbia.edu/research/population-health-methods/content-analysis

Department of Education. (2015). DepEd Order No. 32, Series of 2015 (Adopting the Indigenous Peoples Education Curriculum Framework). Retrieved 14 April 2019, from http://www.deped.gov.ph/2015/07/29/do-32-s-2015-adopting-the-indigenous-peopleseducation-curriculum-framework/

Dillenbourg P. (1999) What do you mean by collaborative learning? In P. Dillenbourg (Ed) Collaborative-learning: Cognitive and computational approaches. (pp.1-19). Oxford: Elsevier Harden, R. (2009). What is a spiral curriculum? https://doi.org/10.1080/01421599979752

Jalilzadeh, K., Tahmasebi, A., \& Jalilzadeh, J. (2011). Constructivism and its implication in curriculum development. In EDULEARN11 Proceedings (pp. 465-467). IATED.

Kagawaran ng Edukasyon. (2016, May). K to12 Gabay Pangkurikulum Social Studies Baitang 1 -10. Retrieved April 13, 2019, from http://www.deped.gov.ph/wp-content/uploads/2019/01/APCG.pdf

Quansah, F. (2018). Traditional or performance assessment: What is the right way to assessing learners. Research on Humanities and Social Sciences, 8(1), 21-24. https://core.ac.uk/download/pdf/234676217.pdf

Republic Act No. 10533 | GOVPH. (2013, May). Retrieved 15 May 2019 from https://www.officialgazette.gov.ph/2013/05/15/republic-act-no-10533/

The Constitution of the Republic of the Philippines | GOVPH. (n.d.). Retrieved 15 May 2019 from https://www.officialgazette.gov.ph/constitutions/1987-constitution/

UNESCO and the Asia/Pacific Cultural Centre for UNESCO (2000) Project EASE - Effective and Affordable Secondary Education. Retrieved 15 May 2019 from http://www.accu.or.jp/litdbase/break/pdf/PHLf922G.PDF 